\title{
Lignin Deposition Converts Juice Sacs to "Brown Thorns" in a Citrus Triploid Hybrid
}

\author{
Zhiyong Hu, Qing Liu, Meilian Tan, Hualin Yi, and Xiuxin Deng ${ }^{\mathbf{1}}$ \\ National Key Laboratory of Crop Genetic Improvement, National Center of Crop Molecular \\ Breeding, Huazhong Agricultural University, Wuhan 430070, China
}

\begin{abstract}
AdDITIONAL INDEX wORDs. polyploidy, enzyme activity, lignification, peroxidase, real-time PCR
AbSTRaCt. In this article, we describe a novel biological phenomenon that the tips of the juice sac of citrus hybrid HRB turned brown and became tough like many "brown thorns"; HRB is a triploid hybrid regenerated from the cross of diploid tangerine BDZ (Citrus reticulata Blanco cv. Huanongbendizao) with an allotetraploid somatic hybrid HR [Hamlin sweet orange (Citrus sinensis Osbeck) + rough lemon (Citrus jambhiri Lush)]. Histochemical analysis indicated that the "brown thorn" of HRB resulted from lignin deposition. The juice sac of HRB had 4.6- and 3.8-fold content of lignin of its parents tangerine and HR, respectively. Microscopy observation of the cross-sections of the juice sac verified that the cell wall of the "brown thorn" was lignified. Moreover, the cell walls near the "brown thorns" were obviously thickened. Analysis of enzyme activity indicated that the peroxidase (POD) activity of HRB was significantly higher than its parents. Quantitative real-time polymerase chain reaction analysis showed that the transcript abundance of the cinnamate 4-hydroxylase $(\mathrm{C} 4 \mathrm{H})$ gene in $\mathrm{HRB}$ was 6.5- and 3.4-fold of its parent $\mathrm{BDZ}$ and HR, respectively, but the POD gene transcript abundance was lower than its parent with $1 / 2$-fold of BDZ and $1 / 7$-fold of HR. These facts led to the conclusion that POD and $\mathrm{C} 4 \mathrm{H}$ were the key regulating factors for lignin biosynthesis in juice sacs of the hybrid HRB. The POD gene, one member of the POD family, with transcript abundance lower than its parent indicated that this POD isoenzyme was not the regulating factor of lignin biosynthesis, and further study should be carried out to determine which POD isoenzyme is the key factor for lignin biosynthesis.
\end{abstract}

Citrus (Citrus L.) is one of the most economically important fruit crops in southern China and in the world. Easy peeling, seedlessness, rich flavor, and aroma have been the main targeted traits for breeding. Biotechnology, especially protoplast fusion and embryo rescue, have greatly promoted citrus breeding (Deng, 2005).

Citrus somatic hybridization techniques can effectively circumvent some of the problems encountered in sexual conventional breeding such as polyembryony and pollen/ovule sterility (Guo et al., 2004). During the past two decades, $\approx 250$ different intergeneric and interspecific somatic hybrids have been produced in the world (Grosser et al., 2000; Guo and Deng, 2001). Many of them were created for breeding parents in interploid crosses to generate seedless triploid scions (Grosser et al., 1998). More recently, $\approx 40$ somatic hybrids have flowered and set fruit, and some are now being used as pollen parents in interploid crosses in the world.

The hybrid HRB was obtained from the cross between the diploid polyembryonic tangerine BDZ (Citrus reticulata cv. Huanongbendizao) and the allotetraploid somatic hybrid HR [Hamlin sweet orange (Citrus sinensis) + rough lemon (Citrus jambhiri)] (Deng et al., 1996). Recently, HRB has flowered and set fruit; fruit contain one to three seeds and have high acid levels, so it is not acceptable as a fresh fruit. The most interesting phenomenon is that tips of some the juice sacs turn brown during fruit ripening and look like many "brown thorns." Investigation showed that "brown thorns" could be

Received for publication 23 July 2007. Accepted for publication 15 Jan. 2008. This research was financially supported by the National Natural Science Foundation of China (Grant no. 30471201), the Ministry of Education (IRT 0548), and 973 project (No. 2006CB708202).

We thank Dr. Qiang Xu, Yunjiang Cheng (in our laboratory), and Prof. F. G. Gmitter, Jr. (HortResearch, USA) for reviewing this manuscript.

${ }^{1}$ Corresponding author. E-mail: xxdeng@mail.hzau.edu.cn. found in all of the $16 \mathrm{HRB}$ plants. This unusual biological phenomenon has not been previously reported in citrus.

\section{Materials and Methods}

Plant materials. Fruit were collected from mature trees (more than 11 years old) of HRB, BDZ, and HR located at the National Citrus Breeding Center of Huazhong Agricultural University. Trees were grafted on trifoliate orange [Poncirus trifoliata (L.) Raf.] and grown in the field under natural conditions.

Ploidy analysis. Ploidy analysis was carried out using a flow cytometer (Partec, Münster, Germany) according to the protocol described by Cheng et al. (2003).

Histochemical anAlysis. Lignin detection was performed as described by Atanassova et al. (1995) on fresh, mature juice sacs. The observation was performed with a stereo microscope (MZ FLIII; Leica, Bensheim, Germany). For toluidine blue staining, tips of juice sacs were fixed in a solution containing $10 \%$ formaldehyde, $50 \%$ ethanol, and $5 \%$ acetic acid in water, dehydrated in an ethanol series $(50 \%, 70 \%, 95 \%$, and $100 \%)$, and embedded in Technovit 7100 resin (Heraeus, Kulzer, Germany). Transversal sections $\approx 1.0 \mu \mathrm{m}$ thick were cut from the embedded blocks using an ultramicrotome (Ultracut R; Leica). The sections were stained with $0.4 \%$ toluidine blue for $5 \mathrm{~min}$. The observations were made with a light fluorescence microscope (BX-61; Olympus, Tokyo). All images were recorded using an Olympus DP 70 CCD camera.

Lignin CONTENT ANALYSIS. Briefly, juice sacs were ground into fine powder. Then $2.0 \mathrm{~g}$ of the sample was hydrolyzed in $8 \mathrm{~mL}$ of $72 \% \mathrm{H}_{2} \mathrm{SO}_{4}$ at $30{ }^{\circ} \mathrm{C}$ for $1 \mathrm{~h}$. Lignin content of juice sacs was quantitatively measured with repeats according to the method described by Zhong et al. (1998).

ENZYME EXTRACTION AND ACTIVITY ASSAYs. Mature juice sacs of HRB, BDZ, and HR were collected and ground under liquid 
Table 1. Specific primers used in relative quantitative real-time reverse transcriptase-polymerase chain reaction of a triploid citrus hybrid and its parents.

\begin{tabular}{llll}
\hline & \multicolumn{1}{c}{ Primer } & $\begin{array}{c}\text { Size } \\
\text { Gene }\end{array}$ \\
\cline { 2 - 3 } (bp)
\end{tabular}

${ }^{\mathrm{z}} \mathrm{C} 4 \mathrm{H}=$ cinnamate 4-hydroxylase, $4 \mathrm{CL}=4$-coumarate:coenzyme $\mathrm{A}$ ligase, $\mathrm{CAD}=$ cinnamyl alcohol dehydrogenase, $\mathrm{POD}=$ peroxidase; $\mathrm{bp}=$ base pair.

$\mathrm{N}_{2}$ and stored at $-70{ }^{\circ} \mathrm{C}$. Phenylalanine ammonialyase (PAL), polyphenoloxidase (PPO), and peroxidase (POD) activities were assayed by the methods described by Sewalt et al. (1997), Galeazzi et al. (1981), and Hammerschmidt and Kuc (1982), respectively. 4-coumarate: coenzyme A ligase (4CL) and cinnamyl alcohol dehydrogenase (CAD) activities were assayed by the methods described by Ran et al. (2005). Each enzyme activity was analyzed at least eight times.

REAL-TIME POLYMERASE CHAIN REACTION QUANTIFICATION. Total RNA was extracted from the mature juice sacs of HRB, BDZ, and HR fruit according to the method described by Liu et al. (2006). Primers (Table 1) were designed with the Primer Express software (Applied Biosystems, Foster City, CA). Isolated RNA was treated with DNase I at $37{ }^{\circ} \mathrm{C}$ for $1 \mathrm{~h}$ to remove any genomic DNA contamination and $20 \mathrm{ng} \cdot \mu \mathrm{L}^{-1}$ of the DNased RNA were used for the first-strand cDNA synthesis using the RevertAid M-MuLV kit (MBI, Vilnius, Lithuania). cDNA samples were diluted in TE buffer at 1:20 and plated in triplicate in adjacent wells at $10 \mu \mathrm{L}$ in a 96-well MicroAmp optical plate (Applied Biosystems). Three wells without any template were also included in each plate as negative controls.
Real-time polymerase chain reaction (PCR) was performed using the ABI 7500 Real Time System (Applied Biosystems). Actin was amplified along with the target gene as the endogenous control in each well to normalize expression among different samples. The control primers $(\beta$-actin) were as follows: forward 5'-CCAAGCAGCATGAAGATCAA- ${ }^{\prime}$ and reverse $5^{\prime}$-ATCTGCTGGAAGGTGCTGAG $-3^{\prime}$. The primers for the target gene and actin were diluted in the SYBER GREEN PCR Master Mix (Applied Biosystems) and $15 \mu \mathrm{L}$ of the reaction mix was added to each well. The probe and primer concentrations in the final $20 \mu \mathrm{L}$ reaction mix were $250 \mathrm{nM}$ and $900 \mathrm{nM}$, respectively, for the target gene and $100 \mathrm{nM}$ and $50 \mathrm{nM}$ for actin. Reactions were performed by an initial incubation at $50{ }^{\circ} \mathrm{C}$ for $2 \mathrm{~min}$ and at $95^{\circ} \mathrm{C}$ for $10 \mathrm{~min}$ and then cycled for 40 times at $95{ }^{\circ} \mathrm{C}$ for $15 \mathrm{~s}$ and $60{ }^{\circ} \mathrm{C}$ for $1 \mathrm{~min}$. The results generated by the instrument on-board software Sequence Detector version 1.3.1 (Applied Biosystems) were transferred to a custom-designed Excel (Microsoft, Seattle, WA) macro for analysis. The differential mRNA expression of each studied gene was calculated with the comparative $\mathrm{Ct}$ method using the formula $2 \Delta \Delta \mathrm{Ct}$. Here, $\Delta \mathrm{Ct}$ stands for the difference between the target gene and the endogenous control, actin, adjusted by the Ct difference between these two genes in negative controls, and $\Delta \Delta \mathrm{Ct}$ equals the difference between the $\Delta \mathrm{Ct}$ values of the target gene in samples.

\section{Results}

Ploidy measurement ANd Simple Sequence RePeat analySIS. Flow cytometry was used to determine the ploidy level of the hybrid HRB. The diploid parent BDZ was used as a control and its absorption peak value was set at channel 50 (Fig. 1A). Peaks of the allotetraploid parent HR were expected at $\approx 100$ (Fig. 1C). The hybrid HRB was triploid with a peak near 75 (Fig. 1B).

Lignin ANALYSIS OF JUICE SACS IN HYBRID HRB. Like its parents BDZ and HR, the fruit of hybrid HRB have a few seeds, and the fruit size is intermediate of its parents (Figs. 2A, 2C, and $2 \mathrm{E})$. The HRB fruit juice sac was granulated, and the fruit tasted sour. Interestingly, "brown thorns" formed in the tips of juice
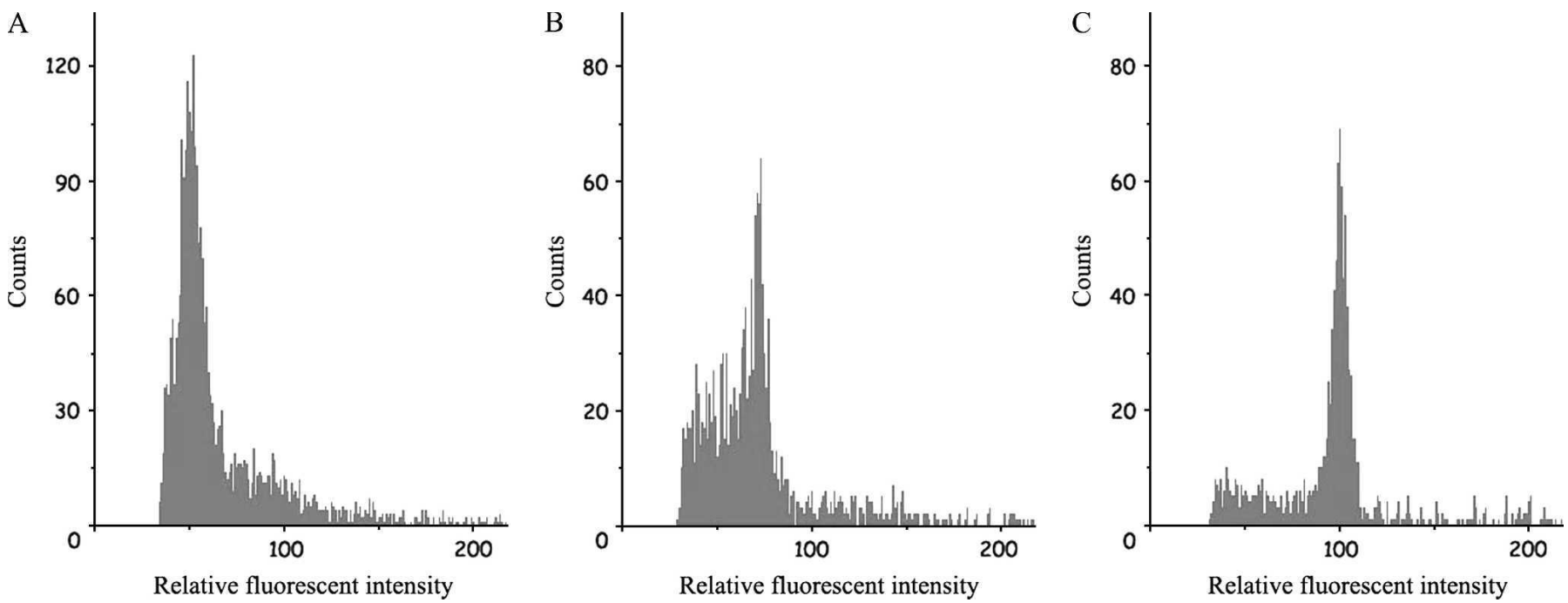

Fig. 1. Ploidy analyses by flow cytometry of (A) BDZ (Citrus reticulata cv. 'Huanongbendizao'), (B) HRB (a hybrid of BDZ and HR), and (C) allotetraploid HR (Citrus sinensis + Citrus jambhiri). Diploid BDZ was used as a control. The results revealed that HRB was triploid and HR was tetraploid. 

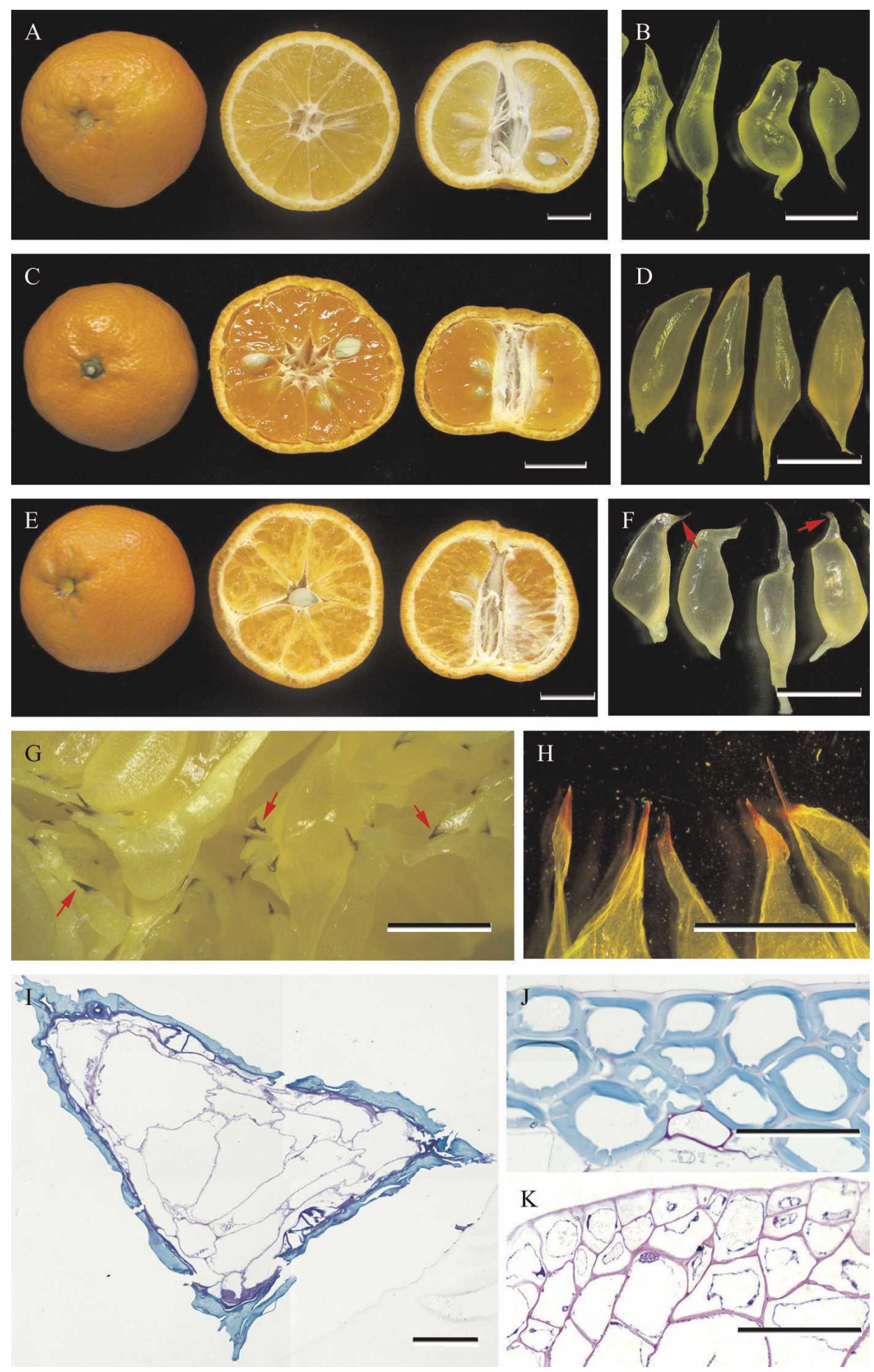

Fig. 2. Phenotype of a citrus hybrid and its parents and histochemical analysis of lignified tissues. (A-B) The fruit and juice sacs of HR (Citrus sinensis + Citrus jambhiri). (C-D) The fruit and juice sacs of BDZ (Citrus reticulata cv. Huanongbendizao). (E-G) The fruit and juice sacs of HRB (a hybrid of BDZ and HR) (arrows indicate the "brown thorns"). (H) The juice sacs of HRB were stained with Wiesner reagent to detect lignin. (I-K) Light microscopy of cross-sections of juice sacs and toluidine blue to stain cell walls. (I) Transverse section of the "brown thorns" in the juice sacs of HRB. (J) Transverse section of the juice sacs near the "brown thorns" in HRB. (K) Transverse section of the juice sacs in HR. Scale bars indicate $2 \mathrm{~cm}(\mathbf{A}, \mathbf{C}, \mathbf{E}) ; 5 \mathrm{~mm}(\mathbf{B}, \mathbf{D}, \mathbf{F}, \mathbf{G}, \mathbf{H})$; or $40 \mu \mathrm{m}(\mathbf{I}, \mathbf{J}, \mathbf{K})$.

sacs (Figs. 2F and 2G), which is quite different from its parents (Figs. 2B and 2D) and other citrus. Histochemical analysis indicated that the "brown thorns" of HRB were the result of lignin deposition (Fig. 2H). Light microscopy of cross-sections of juice sacs revealed lignification in the cell walls of the "brown thorns" (Fig. 2I). Moreover, the cell walls near the "brown thorns" also thickened obviously (Fig. 2J), which was different from that of HR (Fig. 2K). Lignin content in the juice sac of HRB was found to be 4.6-fold and 3.8-fold of its parents BDZ and HR, respectively (Fig. 3).

ENZYME ACTIVITY ANALYSIS ASSOCIATED WITH LIGNIN BIOSYNTHESIS. During the process of lignin biosynthesis, some enzymes play important roles such as PAL, 4CL, CAD, POD, and PPO (Boerjan et al., 2003; Campbell and Ronald, 1996; Whetten and Sederoff, 1995). To investigate the differences between these enzyme activities in the juice sac of hybrid HRB and its parents, the activity of these five enzymes were analyzed (Fig. 4). The results showed that the POD activity of HRB was obviously higher than either of the parents, but the CAD activities were lower. The activities of PAL, 4CL, and PPO enzymes were intermediate in the hybrid HRB compared with the parents.

REAL-TIME POLYMERASE CHAIN REACTION ANALYSIS. All of the $\mathrm{C} 4 \mathrm{H}, 4 \mathrm{CL}, \mathrm{CAD}$, and POD genes are important in the control of lignin biosynthesis (Boerjan et al., 2003; Whetten and Sederoff, 1995). Quantitative real-time PCR analysis indicated that the transcript abundance of the $\mathrm{C} 4 \mathrm{H}$ gene in HRB was higher than its parents BDZ (6.5fold) and HR (3.4-fold); however, the POD gene transcript was less abundant than in its parent BDZ (1/2-fold) and HR (1/7-fold). The other two gene transcripts, 4CL and CAD, were not significantly different between the hybrid and the parents (Fig. 5).

\section{Discussion}

Lignin is crucial for structural integrity of the cell wall and stiffness and strength of plant stems. In addition, lignin waterproofs the cell wall, enabling transport of water and solutes through the vascular system, and plays a role in protecting plants from pathogens (Boerjan et al., 2003). However, juice sacs of citrus fruit are esculent organs, and high lignin deposition in them reduces edibility. 


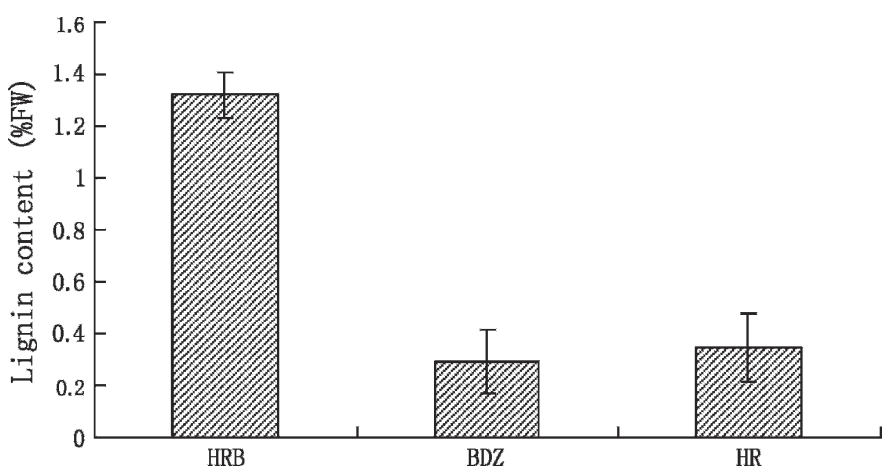

Fig. 3. Lignin content in juice sacs of citrus hybrid HRB and its parents, BDZ (Citrus reticulata cv. Huanongbendizao) and HR (Citrus sinensis + Citrus jambhiri).

The abnormal lignin deposition in the juice sac of hybrid HRB led to the appearance of "brown thorns," but the reason for this biological phenomenon is still unclear. Quiroga et al. (2000) proposed that the last step in the lignin biosynthesis was catalyzed by POD. Our results indicated that the POD activities were obviously higher in the juice sacs of HRB than in the parents, implying that POD played an important role during the abnormal lignin deposition in the juice sac. This observation was consistent with the proposal by Quiroga. Blee et al. (2003) reported that a tobacco (Nicotiana tabacum L.) peroxidase isoenzyme (TP60) was downregulated in tobacco using an antisense strategy, thus affording transformants with lignin reductions of up to $40 \%$ to $50 \%$ in comparison with the wild type. However, the POD gene transcript abundance in juice sacs of HRB was lower than its parents. One possible reason is that the mRNA transcript level and the enzyme activity may not increase simultaneity; that is, when high levels of POD enzyme activity were observed, the mRNA level may have already decreased. Another possible reason is that POD genes in plants belong to a gene family (Duroux and Welinder, 2003) and here only one member of the family was assayed; the one tested might not be associated with lignin biosynthesis. Further study is needed to determine which POD gene family member plays a significant role.

$\mathrm{C} 4 \mathrm{H}$ is a member of the cytochrome $\mathrm{P} 450$ monooxygenase superfamily; it plays a central role in phenylpropanoid metab-

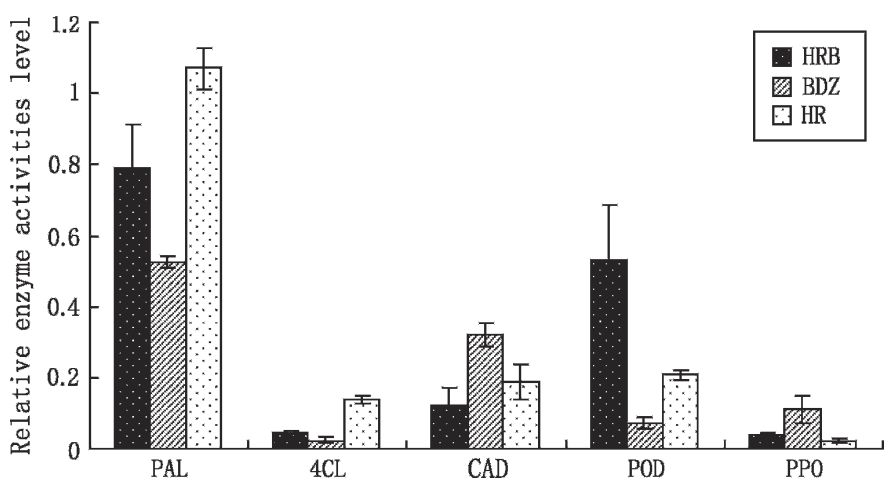

Fig. 4. Enzyme activity analysis in juice sacs of citrus hybrid HRB and its parents, BDZ (Citrus reticulata cv. Huanongbendizao) and HR (Citrus sinensis + Citrus jambhiri). PAL $=$ phenylalanine ammonialyase; $4 \mathrm{CL}=4$ coumarate:coenzyme A ligase; CAD = cinnamyl alcohol dehydrogenase; $\mathrm{POD}=$ peroxidase PPO $=$ polyphenoloxidase .

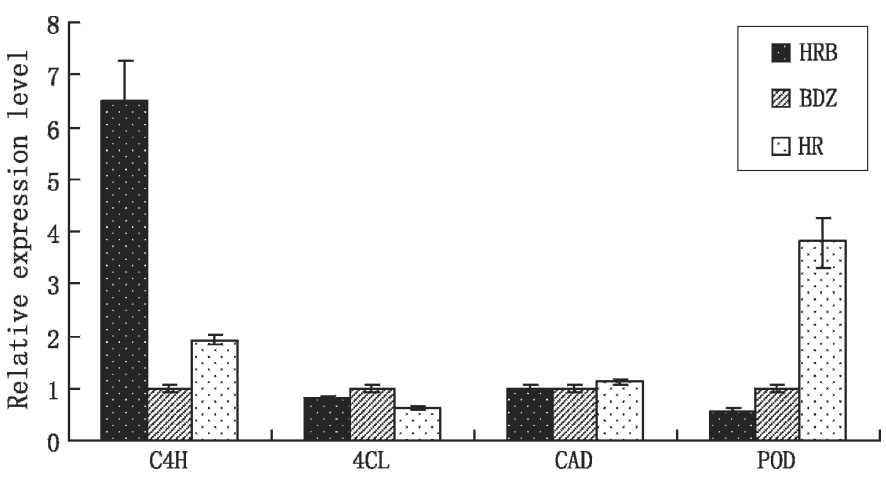

Fig. 5. Relative abundance of mRNA transcripts of four key genes associated with the lignin biosynthetic pathway in juice sacs of citrus hybrid HRB and its parents, BDZ (Citrus reticulata cv. Huanongbendizao) and HR (Citrus sinensis + Citrus jambhiri). $\mathrm{C} 4 \mathrm{H}=$ cinnamate 4-hydroxylase; 4CL = 4-coumarate:coenzyme A ligase; $\mathrm{CAD}=$ cinnamyl alcohol dehydrogenase; $\mathrm{POD}=$ peroxidase

olism and lignin biosynthesis and possibly anchors a phenylpropanoid enzyme complex to the endoplasmic reticulum (Ro et al., 2001). Sewalt et al. (1997) reported that the reduction of $\mathrm{C} 4 \mathrm{H}$ activity by antisense expression or sense suppression resulted in reduced levels of Klason lignin in transgenic tobacco. In this article, we found that the $\mathrm{C} 4 \mathrm{H}$ gene transcript abundance in HRB was higher than in its parents, suggesting that $\mathrm{C} 4 \mathrm{H}$ might be also a key regulating factor of lignin deposition in the juice sacs of hybrid HRB.

Lignification is a complex transcriptional and translational process. Here is the first report of this biological phenomenon in citrus juice sacs; however, this is just a preliminary study, and further work is needed to explain the mechanism conferring this uncommon trait in this triploid citrus.

\section{Literature Cited}

Atanassova, R., N. Favet, F. Martz, B. Chabbert, M.T. Thollier, B. Monties, B. Fritig, and M. Legrand. 1995. Altered lignin composition in transgenic tobacco expressing O-methyltransferase sequences in sense and antisense orientation. Plant J. 8:465-477.

Blee, K.A., J.W. Choi, A.P. O'Connell, W. Schuch, N.G. Lewis, and G.P. Bolwell. 2003. A lignin-specific peroxidase in tobacco whose antisense suppression leads to vascular tissue modification. Phytochemistry 64:163-176.

Boerjan, W., J. Ralph, and M. Baucher. 2003. Lignin biosynthesis. Annu. Rev. Plant Biol. 54:519-546.

Campbell, M.M. and R.R. Ronald. 1996. Variation in lignin content and composition. Plant Physiol. 110:3-13.

Cheng, Y.J., W.W. Guo, and X.X. Deng. 2003. Molecular characterization of cytoplasmic and nuclear genomes in phenotypically abnormal Valencia orange (Citrus sinensis) + Meiwa kumquat (Fortunella crassifolia) intergeneric somatic hybrids. Plant Cell Rpt. 21:445-451.

Deng, X.X. 2005. Advances in worldwide citrus breeding. Acta Hort. Sinica 32:1140-1146 (in Chinese).

Deng, X.X., H.L. Yi, F. Li, W.W. Guo, and W.M. Ye. 1996. Triploid citrus plants obtained from crossing the diploids with allotetraploid somatic hybrids. Acta Bot. Sin. 38:631-636 (in Chinese).

Duroux, L. and K.G. Welinder. 2003. The peroxidase gene family in plants: A phylogenetic overview. J. Mol. Evol. 57:397-407.

Galeazzi, M.A.M., V. Sgarbieri, and S.M. Costantinides. 1981. Isolation, purification and physiocochemical characterization of poly phenol oxidase from dwarf variety of banana (Musa carendishii). J. Food Sci. 46:150-155. 
Grosser, J.W., J. Jiang, F.A.A. Mourao-Fo, E.S. Louzada, K. Baergen, J.L. Chandler, and F.G. Gmitter, Jr. 1998. Somatic hybridization, an integral component of citrus cultivar improvement: I. Scion improvement. HortScience 33:1057-1059.

Grosser, J.W., P. Ollitrault, and O. Fustero. 2000. Somatic hybridization in citrus: An effective tool to facilitate variety improvement. In Vitro Cell. Dev. Biol. Plant 36:434-449.

Guo, W.W. and X.X. Deng. 2001. Wide somatic hybrids of Citrus with its related genera and their potential in genetic improvement. Euphytica 118:175-183.

Guo, W.W., D. Prasad, P. Serrano, F.G. Gmitter, Jr., and J.W. Grosser. 2004. Citrus somatic hybridization with potential for direct tetraploid scion cultivar development. J. Hort. Sci. Biotechnol. 79:400-405.

Hammerschmidt, R. and J. Kuc. 1982. Lignification as a mechanism for induced systemic resistance in cucumber. Physiol. Plant Pathol. 20:61-71.

Liu, Y.Z., Q. Liu, N.G. Tao, and X.X. Deng. 2006. Efficient isolation of RNA from fruit peel and pulp of ripening navel orange (Citrus sinensis Osbeck). J. Huazhong Agr. Univ. 25:300-304.
Quiroga, M., C. Guerrero, M.A. Botella, A. Barceló, I. Amaya, M.I. Medina, F.J. Alonso, S.M. de Forchetti, H. Tigier, and V. Valpuesta. 2000. A tomato peroxidase involved in the synthesis of lignin and suberin. Plant Physiol. 122:1119-1127.

Ran, X., Y. Liang, and J. Li. 2005. Analysis of the lignin contents and related enzymes activities in seed coat between black-seeded and yellow-seeded rapes (Brassica napus L.). Agr. Sci. China 4:890-897.

Ro, D.K., N. Mah, B.E. Ellis, and C.J. Douglas. 2001. Functional characterization and subcellular localization of poplar (Populus trichocarpa $\times$ Populus deltoides) cinnamate 4-hydroxylase. Plant Physiol. 126:317-329.

Sewalt, V.J.H., W. Ni, J.W. Blount, H.G. Jung, S.A. Masoud, P.A. Howles, C. Lamb, and R.A. Dixon. 1997. Reduced lignin content and altered lignin composition in transgenic tobacco down-regulated in expression of 1-phenylalanine ammonia-lyase or cinnamate 4-hydroxylase. Plant Physiol. 115:41-50.

Whetten, R. and R. Sederoff. 1995. Lignin biosynthesis. Plant Cell 7:1001-1013.

Zhong, R., W. Herbert, J. Negrel, and Z.H. Ye. 1998. Dual methylation pathways in lignin biosynthesis. Plant Cell 10:2033-2045. 